\title{
Mapping Perennial Vegetation Cover in the Mojave Desert
}

\author{
cientists with the U.S. Geological \\ Survey's Western Geographic \\ Science Center have recently created \\ a regional map of perennial vegeta- \\ tion cover for the Mojave Desert. The \\ scientists used existing field data col- \\ lected for a variety of previous studies \\ and satellite data available for free \\ through USGS archives to create a \\ calibrated model of percent vegetation \\ cover, an important attribute of desert \\ ecosystems. This map is being used \\ to inform ongoing scientific investiga- \\ tions and land-management efforts, \\ including endangered species habitat \\ mapping and vulnerability and recov- \\ erability studies of desert landscapes \\ in the arid Southwest.
}

The Mojave Desert encompasses approximately 48,000 square miles of arid landscape in southern Nevada, western Arizona, southwestern Utah, and southeastern California. More than a million people live in this desert, which includes Las Vegas, Nevada, one of the fastest growing cities in the southwestern United States. The Mojave Desert is also within a day's drive for 40 million people

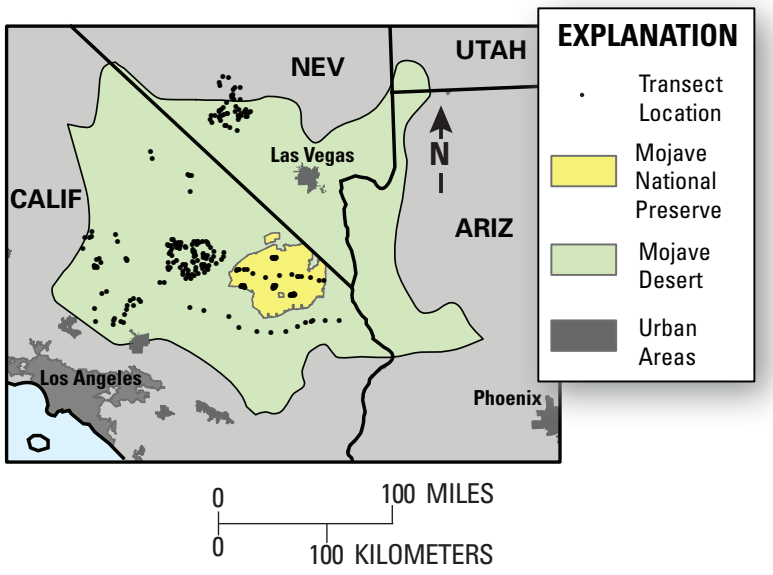

who live in southern California and central Arizona. Lands in the Mojave Desert are managed by a patchwork of entities, including four national park units, six major military training bases, and the Bureau of Land Management (BLM), which manages vast tracks of land in the region. Because of intensive human land uses, land and resource managers routinely make decisions that allow for economic, recreational, and military use, while striving to maintain a healthy desert ecosystem.

Total cover of perennial vegetation (plants that live for more than 2 years) can be considered the single most important attribute of desert ecosystems. Routinely measured in the field using standardized methods, perennial cover affects a number of important ecosystem processes, including soil-moisture
This map shows the Mojave Desert ecoregion (green) and the Mojave National Preserve (yellow). Black dots show locations of measured vegetation transects used by researchers with the USGS Western Geographic Science Center to calibrate MODIS-EVI, Moderate Resolution Imaging Spectroradiometer (MODIS) Enhanced Vegetation Index (EVI), satellite "greenness" data so that it could be used to produce a regional map of perennial vegetation cover. availability, potential evapotranspiration (evaporation and plant transpiration from the land surface to atmosphere), stability of biological soil crusts, wind and water erosion potential, and wildlife habitat. Perennial cover in the Mojave Desert fluctuates between decades with climatic variability, making this cover a key indicator of ecosystem health.

Scientists with the U.S. Geological Survey's Western Geographic Science Center (WGSC) have created a regional map of perennial vegetation cover for the Mojave Desert to better understand the role of perennial vegetation in desert ecosystem health, habitat mapping, dust mitigation, and related studies. Regional mapping of ecological attributes, such as perennial vegetation, forms a crucial component of informed natural-resource management. However, such mapping can be difficult, especially in areas with large tracts of remote terrain, like the Mojave Desert. WGSC scientists derived perennial vegetation cover by coupling Moderate Resolution Imaging Spectroradiometer (MODIS) Enhanced Vegetation Index (EVI) satellite data with vegetation-transect data collected in the field. MODIS-EVI data are available for free through the USGS Glovis 


\section{Dynamics of Mojave Desert Greeness}

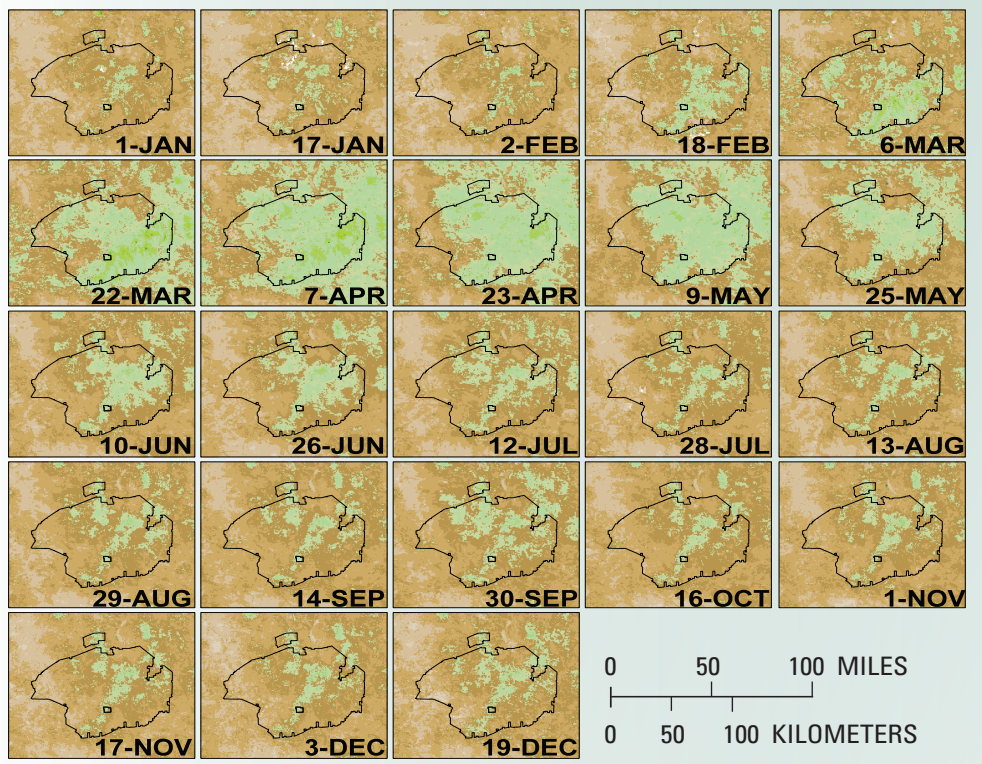

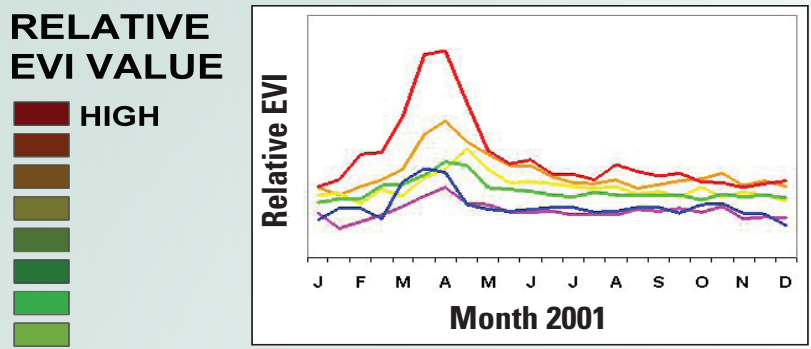

EVI Profiles for 2001. Profile colors correspond to color of field location points in the map below.

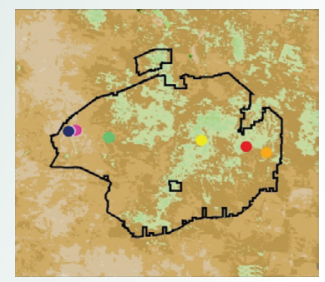

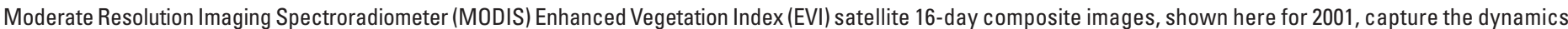

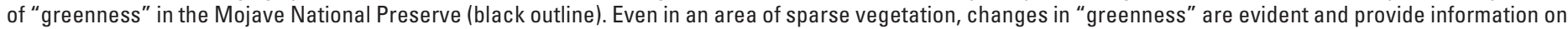
vegetation type and density. USGS scientists coupled these images with field data to model perennial vegetation distribution in this arid landscape.

Web site (http://glovis.usgs.gov/) and offer a regional view of the landscape at frequent time intervals (daily data that are composited over 16-day intervals), revealing the dynamic "greenness" of the landscape, which includes both annual and perennial vegetation that typically exhibit different annual greenness patterns. The field data were used to calibrate the MODIS-EVI data so that differences between these patterns could be used to produce a regional map of perennial vegetation cover.

To create a regional map of perennial vegetation cover for the Mojave Desert ecoregion, WGSC scientists (1) compiled preexisting U.S. Geological Survey (USGS), BLM, and Department of Defense field data that had been collected for a variety of unrelated studies using the same field techniques, (2) evaluated these
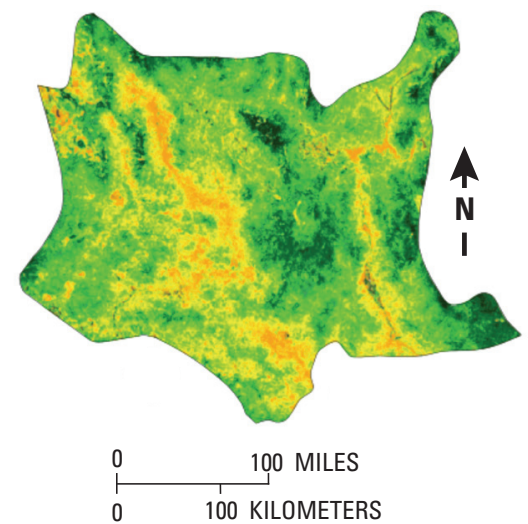

Percent Perennial Vegetation

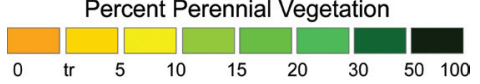

data to determine how representative they are of 250-meter MODIS pixels by examining the complexity of the landscape in the vicinity of the field data points using finer-resolution Landsat Thematic Mapper satellite data, and (3) used stepwise-linear regression models and statistical methods to relate total perennial cover to the MODIS images. The resulting map shows percentage cover of perennial vegetation for the entire Mojave Desert ecoregion with an accuracy of greater than $80 \%$.

This research demonstrates that existing field data, collected for various purposes, can be used effectively with remotely sensed data in modeling total perennial cover. The wealth of vegetation-cover data collected and compiled by USGS personnel over the past century in the Mojave Desert and other areas, as well as the wealth of satellite data available for free through the USGS, offer unparalleled opportunities for scientific investigations.

The Mojave Desert perennial-cover map is being used to inform several ongoing scientific investigations and land-management efforts related to the vulnerability and recoverability of desert landscapes. It is being used by USGS

This computer generated map shows percentage of perennial vegetation cover in the Mojave Desert ecoregion within the area of each 250-meter MODIS satellite pixel. USGS scientists calibrated the data used to create this image on a pixel-by-pixel basis to an overall accuracy of $80 \%$. The resulting map is being used to inform ongoing scientific investigations and land-management efforts related to the vulnerability and recoverability of fragile desert landscapes in the arid Southwest. researchers in studies of dust emissions in the Mojave Desert and to model habitat of the Mojave Desert tortoise (Gopherus agassizii) (http://pubs.usgs.gov/of/2009/1102/).

The work of Western Geographic Science Center (WGSC) scientists mapping perennial vegetation cover in the Mojave Desert is only part of WGSC's efforts to better understand the causes and consequences of land-cover change. WGSC is continuing productive collaborations with public land managers, tribal leaders, and local communities to help ensure that they have the crucial information they need to make informed decisions about ongoing and future land-use choices.

Cynthia S. Wallace

Edited by James W. Hendley II

Graphics and layout by Judy Weathers

For more information, contact:

Cynthia S. Wallace

U.S. Geological Survey

520 N. Park Ave., MS 150

Tucson, AZ 85719

Tel. (520) 670-5589

cwallace@usgs.gov

http://geography.wr.usgs.gov;

http://geography.wr.usgs.gov/science/mojave.html

This Fact Sheet and any updates to it are available at

http://pubs.usgs.gov/fs/2011/3077/ 